\title{
JOSÉ PINTO DE AZEREDO E AS ENFERMIDADES DE ANGOLA: SABER MÉDICO E EXPERIÊNCIAS COLONIAIS NAS ÚLTIMAS DÉCADAS DO SÉCULO XVIII*
}

Jean Luiz Neves Abreu

Universidade Federal de Uberlândia

\begin{abstract}
Resumo
O artigo procura analisar a obra do médico luso-brasileiro José Pinto de Azeredo Ensaio sobre algumas enfermidades d'Angola (1799). A partir dessa obra e de outras fontes, busca-se compreender as ideias e concepções do médico sobre as doenças de Angola e de que maneira elas se relacionam com a medicina das últimas décadas do século XVIII, bem como os aspectos singulares que marcaram sua prática.
\end{abstract}

Pallavras-chave

José Pinto de Azeredo $•$ medicina $\bullet$ século XVIII

\section{Contato}

Universidade Federal de Uberlândia - Campus Santa Mônica

Av. João Naves de Ávila, 2121

Bloco $\mathrm{H}$ - Sala $1 \mathrm{H} 49$

38.400-902 - Uberlândia - MG

E-mail: jeanluiz.na@gmail.com

* Este texto é produto de dois projetos em andamento: "Divulgação de saberes e práticas científicas na América Portuguesa - século XVIII", (financiado pela PROPP - Pró-reitoria de Pesquisa e Pós-graduação - UFU) e "Religião, Natureza e Costumes: gestos, saberes e discursos na América Portuguesa (século XVIII)", na qual atuo como colaborador (financiado pelo CNPq). 


\title{
JOSÉ PINTO DE AZEREDO AND THE DISEASES OF ANGOLA: MEDICAL KNOWLEDGE AND COLONIAL EXPERIENCES IN THE LAST DECADES OF THE XVIII CENTURY
}

Jean Luiz Neves Abreu

Universidade Federal de Uberlândia

\begin{abstract}
The article analyzes the work of the luso-brazilian medicine doctor José Pinto de Azeredo Essay on some diseases of Angola (1799). From the perspective of this work and other sources, we seek to understand the ideas and conceptions of the medicine doctor about the diseases in Angola and how they are relate to medicine in the last decades of the eighteenth century, as well as the unique aspects that have marked his practice.
\end{abstract} Keywords

José Pinto de Azeredo $\bullet$ medicine $\bullet$ eighteenth century.

\section{Contact}

Universidade Federal de Uberlândia - Campus Santa Mônica

Av. João Naves de Ávila, 2121

Bloco H - Sala $1 \mathrm{H} 49$

38.400-902 - Uberlândia - MG

E-mail: jeanluiz.na@gmail.com 


\section{A trajetória de José Pinto de Azeredo e as experiências coloniais}

A expansão portuguesa entre os séculos XVI e XVIII foi marcada, dentre outros aspectos, pela incorporação e difusão de conhecimentos sobre drogas e técnicas médicas nos domínios ultramarinos. O saber médico oriundo das experiências coloniais circulou em compêndios de medicina e outros impressos no Império Português. ${ }^{1}$

No decorrer do século XVIII, vários médicos e cirurgiões tiveram contato com culturas e populações diversas nos domínios portugueses. As obras produzidas a partir desses encontros permitem observar, além da incorporação de saberes locais, o conhecimento acerca das enfermidades que acometiam as populações nos territórios coloniais, bem como a apropriação de várias concepções de medicina pelos médicos luso-brasileiros.

Um dos frutos dessas experiências foi o Ensaio sobre algumas enfermidades d'Angola (1799), de autoria do médico José Pinto de Azeredo. Este artigo busca compreender as formas pelas quais o médico luso-brasileiro fez uso de conhecimentos científicos de sua época e os articulou às suas experiências. Procura-se identificar as principais concepções do saber médico a que ele recorreu, bem como os sentidos adquiridos por esse conhecimento.

Um dos primeiros estudos relativos à sua obra é do também médico Emílio Joaquim da Silva Maia, que em artigo publicado na Revista do Instituto Histórico e Geográfico Brasileiro em 1840, traz breves referências sobre a formação de Azeredo e suas contribuições à medicina brasileira. Silva Maia destaca que o médico foi "Cavaleiro da Ordem de Cristo, Doutor em medicina pela Escola de Edimburgo, membro da sociedade Harveiana da mesma cidade, sócio da Academia das ciências de Lisboa, e médico da Câmara da Sra. D. Maria Primeira". ${ }^{2}$

Sua trajetória e obra, no entanto, carecem de ser mais bem investigadas, na medida em que as referências a elas são muitas vezes imprecisas. ${ }^{3}$ Embora não

\footnotetext{
WISSENBACH, Maria Cristina. Ares e azares da aventura ultramarina: matéria médica, saberes endógenos e transmissão nos circuitos luso-afro-americano. In: MEGIANI, Ana Paula; ALGRANTI, Leila Mezan (Orgs.). O império por escrito: formas de transmissão da cultura letrada no mundo ibérico. São Paulo: Alameda, 2010, p. 375-393; WALKER, Timothy. Acquisition and circulation of medical knowledge within the early modern portuguese colonial empire. In: SHEEHAN, Kevin et al. Science in the Spanish and Portuguese empires 1500-1800. Stanford: Stanford University Press, 2009, p. 247-270.

2 MAIA, Emílio Joaquim da Silva. Elogio histórico do Dr. José Pinto de Azeredo. Revista Trimestral do Instituto Histórico e Geographico Brasileiro, 1840, Tomo II. Rio de Janeiro: Imprensa Nacional, p. 629-635.

3 Sobre a crítica a essas imprecisões ver: PINTO, Manuel Serrano et al. O médico brasileiro José Pinto de Azeredo (1766?-1810) e o exame químico da atmosfera do Rio de Janeiro. História, ciências, saúde-Manguinhos, Rio de Janeiro, v. 12, n. 3, p. 617-673, Dez, 2005, p. 620.
} 
seja o objetivo aqui realizar uma biografia do autor, alguns episódios de sua vida tiveram influência sobre o tratado médico acerca das enfermidades em Angola.

Nascido no Brasil, José Pinto de Azeredo estudou medicina em Edimburgo entre 1786 e 1788, com passagem em Leiden (1788). Na época, Edimburgo era um dos renomados centros de formação médica para onde se direcionavam estudantes nascidos no Brasil e em Portugal, com o apoio do Governo Português. ${ }^{4} \mathrm{~A}$ apropriação de diversas teorias médicas no Reino se deu no âmbito da Universidade de Coimbra e no contato com centros de formação europeus. Apesar de certo ecletismo presente na formação dos profissionais ligados à arte de curar, buscava-se um maior diálogo com o saber médico praticado na Europa e a introdução do experimentalismo na medicina. ${ }^{5}$

Além de proporcionar o contato dos estudantes com as teorias estrangeiras, essas modificações no ensino e o envio de estudantes para outros centros europeus visavam também contornar os problemas da assistência médica nos domínios ultramarinos. O médico português José Manoel Leitão, em seu "Suplemento à História da Cirurgia no qual trata do estado da cirurgia em Portugal", de 1788, comenta a esse respeito que antes de Pombal não havia cirurgiões "para as expedições das frotas comerciais e para o socorro das províncias, onde não havia senão barbeiros que sangravam e meros curandeiros". Em vista disso, o consulado pombalino procurou prover os territórios sob domínio português de médicos e cirurgiões, "não só com obrigações de curar nos hospitais caritativos e militares, mas também de ensinarem anatomia". ${ }^{6}$

A trajetória de José Pinto de Azeredo se insere, portanto, na da geração de médicos que tiveram uma formação ligada à Ilustração e que estabeleceram intercâmbio com as universidades europeias. Além de sua passagem por Edimburgo

\footnotetext{
4 FURTADO, Júnia Ferreira. A medicina na época moderna. In: MARQUES, Rita de Cássia; GERMANO, Beatriz; STARLING, Heloisa M. Murgel (orgs.). Medicina: História em exame. Belo Horizonte: UFMG, 2011, p. 61.

5 Diversos são os trabalhos na historiografia que abordam tais questões, dentre os quais se pode mencionar os seguintes: PITA, João Rui. Medicina, cirurgia e arte farmacêutica na reforma pombalina da Universidade de Coimbra. In: ARAÚJO, Ana Cristina (Coord.). O marquês de Pombal e a universidade de Coimbra. Coimbra: Imprensa da Universidade, 2000, p. 129-162; GUERRA, João Pedro Miller. A reforma pombalina dos estudos médicos. In: CARVALHO DOS SANTOS, Maria Helena. Pombal revisitado. Lisboa: Editorial Estampa, 1984, Vol.1, p. 189-207; ABREU, Jean Luiz Neves. Ilustração, experimentalismo e mecanicismo: aspectos das transformações do saber médico em Portugal no século XVIII. Topoi, Rio de Janeiro, v. 8, 2007, p. 80-104.

6 LEITÃO, Manoel José. Tratado completo de anatomia e cirurgia com um resumo da historia da anatomia e Cirurgia seus progressos e estado dela em Portugal offerecido à Real Junta do Proto-Medicato. Lisboa: Antonio Gomes, 1788, p. 362-365.
} 
e Leiden, onde defendeu trabalhos importantes - a exemplo da elaboração de ensaio sobre as substâncias capazes de agir sobre cálculos urinários e do ensaio sobre a gota, ambos em 1788 -, o exercício da medicina na América Portuguesa e Angola é outro ponto a ser destacado.

Em 1789 ele foi autorizado a exercer medicina em Portugal e nos domínios ultramarinos e nomeado por D. Maria I como físico-mor de Luanda (Angola), com as obrigações de "curar, além do Corpo Militar daquele Reino, os doentes de Hospital da dita Cidade". ${ }^{7}$ Em meados de 1789, Azeredo regressou ao Brasil onde iniciou a prática de medicina e atividades clínicas no Rio de Janeiro, Pernambuco e na Bahia. Do Brasil retornou para Angola, com chegada provável a Luanda em Setembro de 1790. Aí exerceu prática clínica no Hospital Real, lecionando "aula de medicina" a partir do ano seguinte. Azeredo voltaria para Lisboa em 1797, onde viveu até sua morte, em $1810{ }^{8}$

Nessa trajetória por Luanda e pela América Portuguesa, José Pinto de Azeredo pôde extrair várias experiências. Em 1790 publicou um artigo no Jornal Enciclopédico, intitulado Exame químico da atmosfera do Rio de Janeiro, no qual analisava as condições do ar daquela cidade e colocava em prática vários conhecimentos de química. Em Lisboa, escreveu vários manuscritos que não foram impressos, a exemplo de Isagoge Pathologica do Corpo Humano (1802), Curtas Reflexões sobre Algumas Enfermidades Endêmicas do Rio de Janeiro no Fim do Século Passado (manuscrito posterior a 1800); Coleção de Observações Clínicas (posterior a 1803). ${ }^{9}$

Em seus manuscritos fica evidente o desejo de ser reconhecido como médico e como vassalo real. As homenagens prestadas à Rainha D. Maria I e ao Príncipe D. João confirmam o fato de que o conhecimento era importante moeda de troca naquele contexto. Conforme observa Ronald Raminelli, no império luso a produção do conhecimento científico dependia do Estado, que investia na formação dos quadros profissionais e depois os inseria nos quadros da administração colonial

7 Patente de S. Mag. de em que faz Mr.ce ao Doutor José Pinto de Azeredo de Físico Mor deste Reino de Angola - Reproduzida em: Arquivos de Angola, v. IV, n. 41 a 48, p. 149-50, Luanda, 1938. A ortografia foi atualizada na citação.

8 As informações biográficas e a trajetória de José Pinto de Azeredo encontram-se detalhadas no artigo O médico brasileiro José Pinto de Azeredo (1766?-1810) e o exame químico da atmosfera do Rio de Janeiro, sem que aqui seja necessários repeti-las. Cf. PINTO, Manuel Serrano, op. cit., p. 617-638.

9 A referência completa desses manuscritos se encontra no site da Biblioteca Nacional de Lisboa. Disponível em: http://purl.pt/index/geral/aut/PT/152878.html, acessado em 19/04/2011. 
e metropolitana. Atuando a serviço do Estado, os homens de letras buscavam como contrapartida benefícios e reconhecimento. ${ }^{10}$

$\mathrm{Na}$ Oração de sapiência, Azeredo rendia homenagens à Rainha, afirmando ocupar o "lugar de um vassalo agradecido, sendo ao menos por esta causa digno de benévola atenção". ${ }^{11}$ Foi igualmente como fiel vassalo que, anos depois, publicou Ensaios sobre algumas enfermidades d'Angola dedicados ao serenissimo senhor D. João Príncipe do Brasil, em cuja dedicatória afirma ser a obra animada pela proteção de D. João, enaltecido como mecenas e protetor das ciências.

O médico recorreu ao mecenato régio em outras ocasiões. Na tentativa de fazer imprimir seu manuscrito Coleção de observações clínicas, expunha as razões pelas quais sua obra era merecedora de reconhecimento apresentando o seu conhecimento como tributo à Coroa portuguesa:

pelo alto patrocino que mereceram de Vossa Alteza Real os meus Ensaios sobre algumas enfermidades de Angola, me animo a procurar segunda vez a Vossa Alteza Real para proteger a estes meus Escritos. Eles não serão menos felizes do que foram os primeiros se tiverem a fortuna de alcançar um igual acolhimento. Porém, eu não posso duvidar dele quando vejo que Vossa Alteza Real que só respira os desejos de felicitar os seus Povos, me tem elegido entre tantos médicos beneméritos para ser o que cuide na saúde da Tropa. Este meu trabalho, Senhor, é todo feito a beneficio da mesma Tropa: digne-se, pois, Vossa Alteza Real de aceitar a oferta dele como um verdadeiro tributo do meu agradecimento. ${ }^{12}$

A despeito de não ter obtido sucesso com a impressão desse e outros manuscritos, em consideração aos serviços prestados em Angola, José Pinto de Azeredo foi nomeado médico da Real Câmera ${ }^{13}$ obtendo o prestígio almejado e tornando-se um profissional renomado em Portugal. Além disso, como já foi mencionado, tornou-se Cavaleiro da Ordem de Cristo e fez parte do círculo de letrados da Academia das Ciências de Lisboa.

Nesse sentido, a publicação do compêndio sobre as doenças em Angola assumiu um papel estratégico de valorização de suas atividades. A narrativa do médico assume um tom que não disfarça seu narcisismo. ${ }^{14}$ Embora não atribuísse

\footnotetext{
${ }^{10}$ RAMINELLI, Ronald. Viagens ultramarinas: monarcas, vassalos e governos a distância. São Paulo: Alameda, 2008, p. 137.

11 AZEREDO, José Pinto de. Oração de sapiencia feita, e recitada no dia 11 de Setembro de 1791. Manuscrito, Biblioteca Nacional de Lisboa, fl. 03.

12 AZEREDO, José Pinto de. Collecção de observaçoens clinicas. Manuscrito, depois de 1803 , Biblioteca Nacional de Lisboa, fl. 01.

${ }_{13}$ MAIA, Emílio Joaquim da Silva, op. cit., p. 629-635.

${ }^{14}$ MARQUES, Manuel Silvério. A febre, a fibra e o espasmo. In: COUTO, Jorge. et al. Arte médi-
} 
vantagem à sua ciência, nem aos seus talentos e sim "aos progressos da medicina", Azeredo enaltecia o fato de que, graças à sua autoridade de físico-mor em Angola, conseguiu combater os métodos de cura que existiam há anos no país e traziam inúmeros prejuízos à vida humana, bem como instruir os novos estudantes a seguir seus procedimentos, evitando a mortalidade dos enfermos. ${ }^{15} \mathrm{~A}$ partir dessas posições, defendia a contribuição de sua obra para o Estado Português e, ao mesmo tempo, situava seu desempenho como superior ao de seus antecessores.

Se por um lado, a lógica das mercês influi na produção do tratado, devendo-se relativizar a eficácia dos procedimentos proclamados pelo médico; por outro, não se pode deixar de enfatizar os significados que assumem esse testemunho, ao permitir reconstituir aspectos da produção do saber médico a partir de uma trajetória individual no Império Português.

\section{As enfermidades de Angola: entre teorias e experiências}

Com exceção do artigo publicado no Jornal Enciclopédico, dos escritos de José Pinto de Azeredo, o tratado sobre as enfermidades de Angola foi a única obra impressa de que se tem conhecimento. O médico pretendia que seu tratado pudesse trazer informações que viessem a ser úteis para o Governo português, não se prestando somente a reconstituir as condições físicas e mórbidas daquela região. A produção de conhecimentos sobre o império português, nas últimas décadas do setecentos, por funcionários régios e viajantes era essencial para atender às diretrizes da expansão colonial. Estabelecendo redes de conhecimento, os homens de ciência apropriavam-se e manipulavam conceitos do Iluminismo incorporando-os à realidade vivenciada em territórios coloniais. ${ }^{16}$

José Pinto de Azeredo pode ser visto como um típico letrado luso-brasileiro da época, ao realizar uma leitura específica do conhecimento científico indissociável da realidade colonial. As experiências em Angola e na América Portuguesa se incorporam ao repertório de conhecimentos do autor. No prefácio do compên-

ca e imagem do corpo: de Hipócrates ao final do século XVIII. Lisboa: Biblioteca Nacional de Portugal, 2010, p. 7. Disponível em: http://www.centrodefilosofia.com/uploads/pdfs/membros/ desideromurcho/Febre.pdf, acessado em 26/10/2011.

${ }^{15}$ AZEREDO, José Pinto de. Ensaios sobre algumas enfermidades d'Angola dedicados ao Serenissimo Senhor D. João Principe do Brazil. Lisboa: Regia Officina Typografica, 1799, p. VII-X.

${ }^{16}$ Para essas questões ver: KURY, Lorelai. Homens de ciência no Brasil: impérios coloniais e circulação de informação (1780-1810). História, Ciências, Saúde-Manguinhos. v. 11, suplemento 1, 2004, p. 109-129; DOMINGUES, Ângela. Para um melhor conhecimento dos domínios coloniais: a constituição de redes de informação no Império Português em finais do Setecentos. História, Ciências, Saúde - Manguinhos, v. VIII, suplemento, 2001, p. 823-838. 
dio, notava que as "febres de Angola são da mesma natureza daquelas que se observam nos outros países situados na zona tórrida", à semelhança do que havia constatado no Rio de Janeiro, Bahia e Pernambuco.

Nos dois primeiros capítulos do livro, "Ensaios sobre as febres d'Angola" e "Ensaios sobre as febres intermitentes", José Pinto de Azeredo descreve a história, os principais sintomas das febres, as alterações nos órgãos do corpo humano, as teorias sobre as causas da enfermidade e as terapêuticas mais propícias para os casos existentes. Procedimento semelhante é adotado nos dois capítulos seguintes sobre as disenterias e os tétanos, nos quais se descrevem as causas, os sintomas, a história das doenças e os principais métodos de cura utilizados.

Ao discorrer acerca das doenças de Angola, o autor faz uma distinção entre causas "próximas" - relativas às mudanças no organismo - e "remotas" - ligadas aos fatores externos, como o clima, as condições de higiene, dentre outras. Suas referências demonstram que estava atualizado das teorias existentes, fazendo referência a descobertas em diversas áreas. ${ }^{17}$

Dentre o conjunto de conceitos dos quais lança mão para expor a etiologia das febres, Azeredo destaca os princípios de Cullen, que havia sido seu professor e a quem considerava "pai da medicina moderna". ${ }^{18}$ Incorporando os princípios da escola de "economia animal" - voltada para o estudo do papel do sistema nervoso na constituição das doenças, à qual se vinculava o nome de $\mathrm{Cullen}^{19}$-, o médico afirmava que em todas as febres, fossem nervosas ou inflamatórias, era possível observar espasmo na superfície do corpo provocado pela alteração das fibras, levando à sua debilidade "por uma lei geral da economia animal". ${ }^{20}$

Do mesmo modo, Azeredo concede importância aos estudos anatômicos como parte imprescindível de sua formação. Ao investigar as causas das disenterias, afirma que nada "há que mais possa dar uma luz mais clara, e uma ideia mais perfeita da causa próxima da disenteria do que são as dissecações de cadáveres" ${ }^{21}$ Não sem razão o médico dedicou vários manuscritos à anatomia, a exemplo de Estudos anatômicos ${ }^{22}$, onde fazia uma descrição minuciosa das principais partes do corpo humano e suas funções, e outro sobre anatomia dos ossos e vasos linfáticos, no

\footnotetext{
${ }^{17}$ MARQUES, Manuel Silvério, op. cit., p. 3.

${ }^{18}$ AZEREDO, José Pinto de. Ensaios sobre algumas enfermidades d'Angola... op. cit., p. 32.

${ }_{19}$ PORTER, Roy. Das tripas coração: uma breve história da medicina. Rio de Janeiro: Record, 2004, p. 90.

${ }^{20}$ AZEREDO, José Pinto de. Ensaios sobre algumas enfermidades d'Angola... op. cit., p. 34.

${ }^{21}$ Idem, Ibidem, p. 106.

${ }^{22}$ AZEREDO, José Pinto de. Estudos Anatômicos. Manuscrito, Biblioteca Nacional de Portugal, s.d. (antes de 1807).
} 


\section{Jean Luiz Neves ABREU. José Pinto de Azeredo e as Enfermidades de Angola.}

qual trata da osteologia, definida como a ciência que "ensina o estado natural dos ossos". ${ }^{23} \mathrm{Na}$ Oração da sapiência, recitada em 1791, reafirmava o papel da anatomia como ciência que abria "a porta para a verdadeira indagação da natureza". ${ }^{24}$

Tais aspectos colocam a obra de Azeredo em sintonia com o conhecimento médico praticado na Europa no século das Luzes. A despeito das resistências culturais existentes na Europa em relação à anatomia, as dissecações ganhavam cada vez mais relevância para o estabelecimento das causas das enfermidades. $\mathrm{O}$ saber anatômico se torna uma via privilegiada para o conhecimento da natureza do corpo humano e dos progressos da arte de curar. ${ }^{25}$

As referências às diversas teorias sobre as causas das enfermidades são indicativas de como os avanços na medicina exerceram influência em sua obra. Entretanto, Azeredo não se restringiu simplesmente a compilar as teorias e reproduzi-las em seus estudos. Posicionando-se de maneira crítica em relação ao saber médico vigente, defendia que "observação laboriosa, e constante é a única que nos ensina a buscar os meios mais adequados, e prontos para atacar as enfermidades". ${ }^{26}$

Ao tratar dos ciclos das febres, contrapunha-se, por exemplo, às teorias dos médicos que esperavam pelos dias críticos para aplicar medicamentos aos doentes. Neste sentido, afirmava que o próprio Cullen havia caído no erro dos dias críticos: "A invenção dos dias críticos fez com que o professor, esperando pela crise, deixe de continuar com os remédios necessários naquela mesma ocasião". ${ }^{27}$ Referindo-se às causas do tétano, enfatizava o fato de que a maioria dos escritores deixava "em silêncio sua causa próxima" e o método que utilizavam, longe de ser estabelecido no plano científico, era todo empírico. Daí a importância das experiências, exames e hipóteses para se chegar ao conhecimento e apartar os obstáculos aos progressos da medicina. ${ }^{28}$

Em um de seus manuscritos, José Pinto de Azeredo ressaltava ter sido a prática prolongada em diversos hospitais militares que o capacitou para expor a público suas observações. No contato com os doentes pôde descobrir fenômenos que não encontrou em "escrito algum", pondo em prática certos preceitos antigos que eram

${ }^{23}$ AZEREDO, José Pinto de. Anatomia dos ossos, e vasos lymphaticos do corpo humano. Manuscrito, Lisboa, 1791, fl. 01.

${ }^{24}$ AZEREDO, José Pinto. Oração de sapiencia feita, e recitada no dia 11 de Setembro de 1791. Manuscrito, Biblioteca Nacional de Portugal, 1791, fl. 05.

${ }^{25}$ BRETON, David Le. La chair à vif: usages médicaux et mondains du corps humain. Paris: Métailié, 1993, p. 99.

${ }^{26}$ AZEREDO, José Pinto de. Ensaios sobre algumas enfermidades d'Angola... op. cit., p. 4.

${ }^{27}$ Idem, Ibidem, p. 27.

${ }^{28}$ Idem, Ibidem, p. 135-136. 
desprezados e abandonando "outros modernos que não fazem as vantagens que prometem os últimos descobrimentos fisiológicos e químicos". ${ }^{29}$ Deve-se observar que a própria obra sobre as enfermidades em Angola é resultado das observações que fez enquanto físico-mor no hospital. Foi exercendo suas atividades, enquanto médico e professor de "aula de medicina", que ele pode acompanhar de perto o desenvolvimento das enfermidades e seus sintomas.

O hospital representou significativas mudanças no exercício da medicina. A partir do século XVIII esse espaço proporcionou, nas palavras de Michel Foucault, "um olhar da sensibilidade concreta, um olhar que vai de corpo em corpo" permitindo que a teoria se desvanecesse no leito dos doentes, cedendo lugar à experiência. ${ }^{30}$ Além disso, conforme observou Roberto Passos Nogueira, essa instituição contribuiu para transformações da própria organização social da medicina. Se desde a Idade Média a arte médica esteve vinculada ao sistema de corporações, que opunha a formação do médico (físico) e do cirurgião - cabendo ao primeiro a supremacia do conhecimento obtido pelo intelecto e ao segundo as operações manuais e externas -, o hospital representou o ponto de convergência entre o saber teórico dos físicos e o saber técnico dos cirurgiões, ao equiparar as competências desses saberes em um espaço que exigia trabalho colaborativo. ${ }^{31}$

A partir daí, o próprio médico passou a incorporar conhecimentos que antes eram restritos aos cirurgiões e a reconhecer a importância das técnicas cirúrgicas para o diagnóstico das doenças. A medicina e a cirurgia passaram a figurar como especialidades médicas na medida em que a formação dessas categorias técnicas-profissionais pressupunha uma prévia formação comum, incluindo a anatomia, a fisiologia, a patologia, dentre outras disciplinas. ${ }^{32}$

Enquanto a homogeneização da medicina e da cirurgia se estabeleceu em universidades europeias desde meados do século XVIII, em Portugal foi somente após a aprovação dos Estatutos da Universidade de Coimbra de 1772 que a formação dos médicos passou a incorporar esses preceitos. No texto dos Estatutos

\footnotetext{
${ }^{29}$ AZEREDO, José Pinto de. Colleç̧ão de observaçoens clinicas. Manuscrito, op. cit., fl. 01.

${ }^{30}$ FOUCAULT, Michel. O nascimento da clínica. Rio de Janeiro: Forense Universitária, 2001, p. 137.

${ }^{31}$ NOGUEIRA, Roberto Passos. Do físico ao médico moderno: a formação social da prática médica. São Paulo: UNESP, 2007, p. 71-79. A divisão entre medicina e cirurgia presente até meados do século XVIII na Europa equivalia à divisão entre a ciência e a técnica; atividades intelectuais e atividades práticas. A aproximação entre médicos e cirurgiões foi importante para avanços da técnica médica e para o conhecimento do corpo e das doenças a partir dos estudos anatômicos. Para essa discussão ver também: FIGUEIREDO, Betânia Gonçalves. A arte de curar: cirurgiões, médicos, boticários e curandeiros no século XIX em Minas Gerais. Rio de Janeiro: Vício de Leitura, 2002, p. 64-72.

${ }^{32}$ NOGUEIRA, Roberto Passos, op. cit., p. 87.
} 
considerava-se ter sido o divórcio entre a medicina e cirurgia "prejudicial aos progressos da arte de curar e funesto à vida dos homens não sendo possível que seja bom médico, quem não for ao mesmo tempo cirurgião", e determinava-se que "sejam todos os médicos ao mesmo tempo cirurgiões". ${ }^{33}$

A despeito da existência de diferenças entre cirurgiões e médicos ainda presentes nos Estatutos, almejava-se para os médicos uma formação mais abrangente, que iria ser completada pelos hospitais. A esse respeito, Jorge Crespo comenta que no contexto português o hospital se constituiu como o "lugar privilegiado da aquisição da experiência médica científica, o espaço onde surgia a oportunidade mais fecunda da aproximação com a diversidade das doenças e das misérias da comunidade". ${ }^{34}$

A formação de José Pinto de Azeredo e sua atuação em Angola convergem para esses aspectos que definiriam o exercício da medicina a partir do século XVIII, fundados no estreitamento entre teoria e empiria, atributos exercitados no contato cotidiano com os enfermos nos leitos dos hospitais. Mas para estabelecer as possíveis causas das moléstias, o médico deveria também observar a natureza e os costumes.

\section{Natureza e costumes}

No Ensaios sobre algumas enfermidades d'Angola há várias passagens relativas ao clima, à geografia e às condições de vida. O compêndio fornece informações que permitem reconstituir as condições de vida dos habitantes em Angola, os alimentos mais comuns, as práticas de cura utilizadas pelos empíricos. Analisando as "causas remotas" das febres, Azeredo afirmava que não podia deixar de se ocupar de uma descrição do país:

O seu terreno, as suas águas, as suas plantas, a sua atmosfera, os seus ventos, os seus costumes, os seus alimentos oferecerão talvez a um espírito indagador interessantes notícias, pelas quais ele descubra os meios mais eficazes de prevenir, e de remediar tantos males. ${ }^{35}$

O médico atenta principalmente para as condições físicas e ambientais encontradas em Angola. A respeito da hidrografia, destaca as características dos mananciais de água do país, informando que o rio Bengo fornecia água com qualidade péssima aos habitantes, por ser um "veículo de carne humana corrupta", já que os habitantes tinham o hábito de lançar nele vários despojos. Devido às condições

\footnotetext{
${ }^{33}$ Estatutos da Universidade de Coimbra de 1772. Livro III, Cursos das Sciencias nauturaes e filosóficas. Coimbra, 1972, Edição Fac-Símile, p. 20.

${ }^{34}$ CRESPO, Jorge. A história do corpo. Lisboa: DIFEL, 1990, p. 99.

${ }^{35}$ AZEREDO, José Pinto de. Ensaios sobre algumas enfermidades d'Angola..., op. cit., p. 36.
} 
climáticas pouco favoráveis, como a raridade das chuvas, salientava a utilidade das poucas árvores e dos vegetais existentes, pois forneciam "ar puro para o homem respirar e viver". Daí a importância da conservação das florestas capazes de oferecer "quantidade de resinas e bálsamos odoríferos" corretivos da corrupção do ar. Sublinhava igualmente a importância de algumas espécies vegetais para o sustento e conservação da saúde, fornecendo remédio para o escorbuto, o "mal de Luanda". ${ }^{36}$

Para Azeredo o sol era um dos principais motivos responsáveis por tornar o clima "pestífero". Sob ele caía o homem mais forte e robusto, como os oficiais militares, que antes de chegar a Angola tinham perfeita saúde. Nesse sentido, salientava a dificuldade de aclimatação dos europeus. Embora a doença pudesse atingir qualquer pessoa, atingia com mais frequência e intensidade os que chegavam à costa da África e não se acostumavam ao sol, os quais, "pelo costume que trazem dos outros climas benignos, são atacados com maior força, e com maior perigo". ${ }^{37}$

As exalações das águas do rio Bengo no tempo das chuvas possuíam semelhante efeito nocivo à saúde, consideradas como um "veneno para o corpo", por tornar o "ar crasso, pestilento e incapaz de respirar". ${ }^{38}$ Ao lado das intempéries climáticas, o médico discorria sobre outros motivos que concorriam para a impureza da atmosfera, como imensa quantidade de escravos que se acumulavam nas casas dos comerciantes até serem transportados para o Brasil, as casas de palha que com as chuvas apodreciam e os cadáveres que ficavam enterrados nas igrejas, "indubitáveis motivos de mil doenças". Tais condições deveriam ser objeto de estudos e "desvelos daqueles que vigiavam o bem público" para a conservação da saúde nas povoações. ${ }^{39}$

A associação entre a qualidade do ar e as enfermidades já havia sido objeto da reflexão de José Pinto de Azeredo no artigo, publicado no Jornal Enciclopédico, sobre a qualidade do ar no Rio de Janeiro. Ao longo de sua análise, postulava que em decorrência das descobertas da ciência moderna e da química tornava-se possível examinar mais profundamente a atmosfera, distinguindo a qualidade de três tipos de ar e seus efeitos diversos no organismo: o ar puro, o ar fixo e o ar mophete, de natureza praticamente desconhecida. Após medir a quantidade de cada um desses "ares" no Rio de Janeiro, constatou que a atmosfera da cidade continha menos ar puro e fixo e mais ar mophete que na Europa. Argumentava ser talvez aquele ar, "atraindo os vapores maus

\footnotetext{
${ }^{36}$ Idem, Ibidem, p. $37-44$.

${ }^{37}$ Idem, Ibidem, p. 5.

${ }^{38}$ Idem, Ibidem, p. 46-49.

${ }^{39}$ Idem, Ibidem, p. 51.
} 


\section{Jean Luiz Neves ABREU. José Pinto de Azeredo e as Enfermidades de Angola.}

das lagoas, e águas encharcadas ainda servindo de alimentos a certos insetos que atacam o nosso corpo (...), a causa condutora das enfermidades". ${ }^{40}$ As conclusões a que chega, apesar do emprego de métodos modernos, rendem-se aos pontos de vista mais tradicionais sobre a insalubridade do clima tropical. ${ }^{41}$

Tendo por base tais pressupostos, Azeredo estabelecia um diálogo com vários textos de medicina publicados em Portugal nas últimas décadas do século XVIII. O médico português Francisco José de Almeida, por exemplo, sustentava opinião semelhante sobre a influência da atmosfera na boa saúde do corpo: "na atmosfera bebemos a saúde e a doença; as epidemias aqui se fomentam, e se propagam". Não era preciso mais do que "ela estar encerrada por algum tempo para perder a sua elasticidade, ensopando-se talvez em vapores estranhos". Desaconselhava, nesse sentido, a circulação das pessoas em locais fechados, já que neles todos os animais se "abafam, entristecem e adoecem em um lugar fechado". ${ }^{2}$

Se em Portugal a qualidade da atmosfera trazia danos à saúde, as condições naturais das regiões tropicais tornavam ainda mais suscetíveis as doenças de colonos e escravos. No Tratado da conservação da saúde dos povos (1756), o médico português Antônio Ribeiro Sanches não apenas enfatizava o calor contínuo de regiões como o Brasil e a Costa da Mina, como observava que em Portugal e em Angola, onde inundam tantos rios, e em toda a América, "depois das inundações, logo que as matérias das enxurradas começam a apodrecer, o ar infecta-se e produz semelhante podridão nos corpos: manifesta-se por toda a sorte de febres podres, e, sobretudo, por disenterias". ${ }^{43}$

\footnotetext{
${ }^{40}$ Exame químico da atmosfera do Rio de Janeiro, feito por José Pinto de Azeredo, doutor em medicina pela Universidade de Leyde, físico-mor, e professor de medicina do Reino de Angola. Jornal enciclopédico. Artigo I: História Natural fysica e química. Lisboa, Março, 1790, p. 259285. Para um exame detalhado das teorias sobre o ar atmosférico consultar: PINTO, Manuel Serrano et. al., op. cit.

${ }^{41} \mathrm{O}$ texto sobre a qualidade do ar do Rio de Janeiro foi analisado por Lorelai Kury, que também faz menção ao fato de o autor se vincular ao determinismo climático acerca dos trópicos, típico da literatura do século XVIII. Entretanto, a autora observa que na passagem para o século XIX é possível notar um confronto entre esses pontos de vista, pelo menos no tocante ao Rio de Janeiro. KURY, Lorelai. Rio de Janeiro: a cidade e os médicos no período joanino. In: FLECK, Eliane Cristina Deckmann; SCOTT, Ana Silva Volpi. A corte no Brasil: População e sociedade no Brasil e em Portugal no início do século XIX. São Leopoldo: Oikos; Editora Unisinos, 2008, p. 119-134.

${ }^{42}$ ALMEIDA, Francisco José de. Tratado de educação fysica dos meninos para uso da nação Portuguesa. Lisboa: Officina da Academia Real de Ciências, 1791, p. 19-21.

${ }^{43}$ SANCHES, Antônio Nunes Ribeiro. Tratado da conservação da saúde dos povos obra útil, e igualmente necessária aos magistrados, capitães generais, capitães do mar, e guerra, prelados, abadessas, médicos e pais de família com um apêndice, considerações sobre os terremotos, com a noticia dos mais consideráveis de que faz menção a história, e dos últimos que se sentiram na Europa desde I de Novembro de 1755. Lisboa: Officina Joseph Filipe, 1757, p. 46.
} 
Dessa maneira, as percepções desses doutores se rendem ao pessimismo climático vigente no pensamento naturalista e médico desse período acerca dos trópicos. Conforme observa David Arnold, a "invenção dos trópicos" a partir da expansão ultramarina trouxe, ao lado da visão paradisíaca, representações negativas que se convertem em lugares comuns na literatura de viagem do século XVIII. A literatura sobre a África Ocidental e o Caribe reforçou as imagens do clima inclemente e das enfermidades que acometiam os colonos de forma violenta. Exemplo disso é o Treatise on tropical diseases and on the climate of the West Indies (1787), de autoria de Benjamin Moseley, no qual se considerava que a transição dos climas temperados para os quentes era doentia para natureza humana. ${ }^{44}$

A concepção de que o clima agia sobre o organismo humano ganhou força pelas doutrinas médicas em voga. Tendo por base a concepção hipocrática da influência dos ares e lugares sobre a saúde e os temperamentos, forjou-se o conceito de "constituição epidêmica", em que o estudo da doença não se centraria no indivíduo, mas na investigação de um conjunto de dados. O médico inglês Sydenham foi um dos precursores do pensamento classificatório das enfermidades, definindo uma abordagem histórica e geográfica da doença a partir do estudo das condições naturais, como a qualidade dos solos, climas e as estações de chuva. Base do neo-hipocratismo, as análises das doenças envolviam as topografias (a situação dos lugares, o terreno, a água, o ar, a sociedade, os temperamentos dos habitantes), observações meteorológicas, análise das epidemias, doenças reinantes e descrição dos casos extraordinários. ${ }^{45}$

Atrelada às influências climáticas sobre a constituição das enfermidades estava a dos "miasmas", termo que designava a infecção do ar por gases ou vapores pútridos. Partia-se do princípio de que o ar entrava "na própria tessitura dos organismos vivos" e agia de múltiplas maneiras sobre esses, "por simples contato com a pele ou com a membrana pulmonar, por substituições através dos poros, por ingestão direta ou indireta". ${ }^{46}$

Como é possível observar, José Pinto de Azeredo se mostrava tributário dessas concepções e as incorporou em seu livro. O conhecimento dessas teorias se efetivou não apenas pela sua formação em Edimburgo ou a experiência na América Portuguesa e Angola. O contato com a literatura produzida sobre os

\footnotetext{
${ }^{44}$ ARNOLD, David. La natureza como problema histórico. El médio, La cultura y La expansión de Europa. México: Fundo de Cultura Económica, 2000, p. 138-139.

${ }^{45}$ FOUCAULT, Michel, op. cit., p. 23-26.

${ }^{46}$ CORBIN, Alain. Saberes e odores: o olfato e o imaginário social nos séculos dezoito e dezenove. São Paulo: Companhia das Letras, 1987, p. 19.
} 
trópicos exerceu igual importância em suas formulações, dentre as quais citava a obra de John Hunter, Observations on the Diseases of the Army in Jamaica, de 1788. Tais elementos demonstram os caminhos por que a literatura científica do período chegava às mãos dos médicos em Portugal, indicando os processos pelos quais o saber médico europeu se difundiu nos domínios portugueses.

Além das condições atmosféricas e climáticas, Azeredo se detém na descrição dos costumes dos habitantes de Angola. Para o médico, o comportamento da população e suas crenças contribuíam para a intensidade das febres. Dentre esses, reprovava os hábitos de cura dos africanos, afirmando que: nas "suas moléstias [eles] não querem professores, nem tomam remédio de botica, porque só têm fé nos seus medicamentos", administrados por "feiticeiros" ou "curadores". Lamentava ainda o fato de alguns brancos e europeus acreditarem na virtude dos remédios vendidos por "empíricos negros". Recorrer a tais artifícios era fruto da ignorância, e razão de muitas desgraças que tornavam moléstias benignas mortais. ${ }^{47}$

As posições de repúdio aos curandeiros e feiticeiros por parte de Azeredo exprimem uma atitude comum aos médicos ilustrados em Portugal. Tema recorrente na medicina europeia, a rivalidade entre os representantes da arte oficial de curar e as práticas informais ganha uma nova dimensão no século XVIII. Como analisa Márcia Moisés Ribeiro, nesse contexto, assiste-se a um movimento de racionalização contra as práticas mágicas e seus praticantes, desdobramento da mentalidade ilustrada e das reformas da medicina em Portugal. ${ }^{48}$

Para além de recorrerem às práticas informais de cura, Azeredo descreve outros hábitos de igual modo reprováveis. É o caso da tradição de carpir os mortos, "origem de excessos, de irreligião, e de enfermidades" para a qual, nem a pregação da Igreja, nem o braço secular eram suficientes para colocar término. $\mathrm{O}$ médico repreendia o fato de que o costume entre os angolanos de conservar o corpo do cadáver a fim de prestar-lhe homenagem era sempre acompanhado de muito vinho, alo (bebida fermentada feita de milho), e aguardente do Brasil, levando ao uso imoderado dos "licores espirituosos" e propiciando as "moléstias endêmicas do clima".

O autor correlacionava as febres também ao comportamento sexual, observando: "um só ato venéreo em África produz tanta debilidade, quanto pode induzir uma larga sangria". Para justificar tal posição recorria a argumentos científicos

${ }^{47}$ AZEREDO, José Pinto de. Ensaios sobre algumas enfermidades d'Angola..., op. cit.,p. 53.

${ }^{48}$ RIBEIRO, Márcia Moisés. Exorcistas e demônios: demonologia e exorcismo no mundo luso-brasileiro. Rio de Janeiro: Campus, 2003, p. 172-178. 
de que o excesso das atividades sexuais enfraquecia os nervos e a relaxação dos órgãos não sustentavam o "peso da máquina" do corpo humano. Descrevia ainda os hábitos alimentares e de higiene, mencionando como o "abuso das pesadas ceias", a "falta de limpeza do corpo e pouco asseio nos vestidos" influíam em muito para as moléstias. Dentre os alimentos mais comuns menciona a quicoanga, que era a mandioca apodrecida debaixo d'água chamada no Brasil de $P u b a^{49}$, e os matetes, papas ralas feitas de fubá ou farinha de milho. Considerava deficitário o regime dietético dos negros, pois estes se sustentavam com muito pouco alimento e no tempo das secas comiam insetos, gafanhotos e outros animais. ${ }^{50}$

Ao lado do exame dos sintomas, dos exames anatômicos, os hábitos de vida forneciam um importante caminho para os médicos chegarem às causas das enfermidades. Na conjuntura em que José Pinto de Azeredo publicou seu tratado, compêndios de medicina que circularam na Europa e no mundo ibérico se voltavam para a normatização dos hábitos cotidianos e para a higiene, destinados a instruir as famílias sobre como conservar a saúde, o que enfatiza a associação entre as enfermidades e os comportamentos alimentares e higiênicos das populações. ${ }^{51}$

Outro aspecto a ser sublinhado diz respeito ao fato de José Pinto de Azeredo se ater principalmente à descrição dos costumes e hábitos dos negros, dando ênfase às precárias condições em que viviam. As informações sobre as doenças provenientes da África constituíram um tema relevante da medicina em Portugal, presente em compêndios de matéria médica no decorrer do setecentos que contribuíram para demarcar a etiologia das moléstias, suas causas, bem como as terapêuticas úteis aos senhores de escravos para males como o escorbuto. ${ }^{52} \mathrm{Nas}$

\footnotetext{
${ }^{49}$ O militar Elias Alexandre da Silva Corrêa, que viveu em Angola no século XVIII, em sua História de Angola, também menciona a quicoanga, afirmando que os negros a preferiam à farinha. $\mathrm{Cf}$. PEREIRA, Magnus. Rede de mercês e carreira: o "desterro d'Angola" de um militar luso-brasileiro (1782-1789). História. Questões e Debates, v. 45, 2007, p. 97-128, p. 121.

${ }^{50}$ AZEREDO, José Pinto de. Ensaios sobre algumas enfermidades d'Angola..., op. cit., p. 54-60.

${ }^{51}$ Para essa questão na medicina europeia ver: PORTER, Roy. The popularization of medicine, 1650-1850. Londres: Routledge, 1992. No caso do mundo ibérico e do contexto luso-brasileiro ver, entre outros: PERUGA, Mónica Bolufer. "Ciência de la salud" y "Ciencia de las costumbres": higienismo y educación en el siglo XVIII. Revista de Ciencias Sociales, n. 20, 2000, p. 25-50; ABREU, Jean Luiz Neves. Higiene e conservação da saúde no pensamento médico luso-brasileiro do século XVIII. Asclepio, Madrid, v. 62, 2010, p. 225-250; MARQUES, Vera Regina Beltrão. Instruir para fazer a ciência chegar ao povo no Setecentos. Varia história, n. 32, 2004, p. 37-47.

${ }^{52}$ Para as informações sobre as doenças africanas nos tratados de medicina luso-brasileiros e seus significados ver: FURTADO, Júnia Ferreira. A medicina no império marítimo português. op. cit., p. 104-105; WISSENBACH, Maria Cristina Cortez. Cirurgiões do Atlântico Sul - conhecimento médico e terapêutica nos circuito do tráfico e da escravidão (séculos XVII-XIX). Anais do XVII Encontro Regional de História - O lugar da História. Campinas: ANPUH/SP-UNICAMP, 6 a 10 de setembro de 2004. Cd-rom, p. 1-10.
} 
últimas décadas do século XVIII, como bem lembra Rafael de Bivar Marquese, o saber médico passou a ser "visto como um instrumento fundamental ao desenvolvimento colonial, dada a percepção dos impactos que as doenças tropicais causavam na população branca e escrava". ${ }^{53}$ No contexto luso-brasileiro, as doenças dos escravos passaram a merecer mais atenção e a figurar como objeto de diversos textos produzidos por letrados luso-brasileiros, além da tradução de tratados estrangeiros que versavam sobre o assunto. ${ }^{54} \mathrm{O}$ Ensaios sobre algumas enfermidades d'Angola se insere, portanto, nesse movimento de inovação da medicina em Portugal, como também está atrelado às questões específicas associadas à produção do conhecimento, caso das enfermidades dos negros.

\section{0 universo da cura}

Após proceder ao exame das causas das moléstias, Azeredo propõe diversas terapias para as febres, disenterias e tétanos. Neste ponto, o autor transita entre as práticas reconhecidas pela tradição e as conclusões obtidas a partir da observação. Ao se referir à cura das febres, afirmava que sempre respeitara a autoridade de alguns autores, mas nunca havia se fiado nela: "O curativo das febres que apresento, as observações sobre a aplicação dos remédios, as experiências sobre o bom êxito deles, são resultados da minha diligência, e do meu estudo". ${ }^{55}$

A posição de Azeredo acerca das práticas de cura reafirma o princípio de que na medicina exercida nos domínios ultramarinos portugueses a observação empírica foi componente importante para o conhecimento de enfermidades pouco conhecidas na Europa e cujas causas e tratamentos eram desconhecidos. No movimento denominado por Luiz Felipe de Alencastro de "união microbiana do mundo", enquanto os europeus disseminaram a varíola, a rubéola e doenças venéreas, os africanos transmitiram aos portos europeus moléstias como a dracunculose (filariose do aparelho circulatório, conjuntivo e das cavidades serosas), causando a elefantíase, dentre outras enfermidades. ${ }^{56} \mathrm{Em}$ contato com condições geográficas e climáticas diferentes e doenças pouco conhecidas em Portugal,

\footnotetext{
${ }^{53}$ MARQUESE, Rafael de Bivar. Feitores do corpo, missionários da mente: senhores, letrados e o controle dos escravos nas Américas, 1660-1680. São Paulo: Companhia das Letras, 2004, p. 96.

${ }^{54}$ Essa questão foi desenvolvida em ABREU, Jean Luiz Neves. A Colônia enferma e a saúde dos povos: a medicina das 'luzes' e as informações sobre as enfermidades da América portuguesa. História, Ciências, Saúde - Manguinhos, Rio de Janeiro, v. 14, n. 3, jul.-set. 2007, p. 761-778,

55 AZEREDO, José Pinto de. Ensaios sobre algumas enfermidades d'Angola..., op. cit., p. 61.

${ }^{56}$ ALENCASTRO, Luiz Felipe de. O trato dos viventes: Formação do Brasil no Atlântico Sul. São Paulo: Companhia das Letras, 2000, p. 128.
} 
os oficiais de medicina tiveram que buscar formas de combater as doenças que acometiam colonos e escravos, as quais não eram redutíveis às teorias existentes, incapazes de darem conta da diversidade de fatores relacionados às enfermidades em locais como a África e a América Portuguesa. ${ }^{57}$

Em contato com as práticas de cura utilizadas na época em que esteve em Angola, Azeredo expunha as controvérsias existentes em torno da aplicação de alguns medicamentos e sua eficácia. No caso da disenteria, conforme apontava, não havia consenso sobre o uso do ópio, afirmando que enquanto Sydenham confiava toda a cura na sua utilização, outros o condenavam totalmente. Para ele, os efeitos benéficos do ópio eram enganosos, pois passado seus primeiros efeitos, as dores logo retornavam. ${ }^{58}$

Azeredo censurava de semelhante maneira a utilização dos remédios caseiros prescritos pelos empíricos e curandeiros, tidos como responsáveis pelas muitas causas de morte no caso das febres. Em várias passagens enfatizava a necessidade de bastante cautela no uso de sangrias, uma das práticas mais comuns para a cura de muitas doenças, tanto no universo da medicina popular quanto da erudita. ${ }^{59} \mathrm{~A}$ respeito da sangria afirmava: a "lanceta tem sido de bem funestas consequências, sendo governada por aqueles que só têm lido as obras de Sydenham. Eu tenho aprendido que a perda de uma pequena quantidade de sangue senão faz logo um evidente mal também nunca faz benefício algum" ${ }^{60}$ No tratamento da disenteria, confessou ter "feito sangrar algumas vezes", embora nunca considerasse que essa trouxesse algum benefício. Avaliava que esse procedimento não convinha em muitas moléstias, sendo a disenteria uma delas. ${ }^{61}$ Mesma opinião exprimia em

\footnotetext{
${ }^{57}$ Sobre esse aspecto consultar, entre outros: FURTADO, Júnia Ferreira. A medicina no império marítimo português. In: MARQUES, Rita de Cássia; GERMANO, Beatriz; STARLING, Heloisa M. Murgel (Orgs.). Medicina: História em exame. Belo Horizonte: UFMG, 2011, p. 92-93. RIBEIRO, Márcia M. Nem nobre, nem mecâncico... a trajetória social de um cirurgião na América portuguesa do século XVIII. Almanack Braziliense, v. 2, 2005, p. 64-75. Disponível em: www. almanack.usp.br; WISSENBACH, Maria Cristina Cortez. Gomes Ferreira e os símplices da terra: experiências sociais dos cirurgiões no Brasil-Colônia In: FERREIRA, Luís Gomes. Erário Mineral. Belo Horizonte; Rio de Janeiro: Fundação João Pinheiro, Centro de Estudos Históricos e Culturais; Fundação Oswaldo Cruz, 2002, p. 107-149.

${ }^{58}$ Idem, Ibidem, p. 118

${ }^{59}$ Sobre a prática da sangria no universo da medicina europeia e em particular na portuguesa ver: SANTOS, Georgina Silva dos. A arte de sangrar na Lisboa do Antigo Regime. Tempo, Rio de Janeiro, n. 19, jul. 2005, p. 43-60; CARNEIRO, Henrique. Filtros, mezinhas e triacas: as drogas no mundo moderno. São Paulo: Xamã, 1994, p. 83-84.

${ }^{60}$ AZEREDO, José Pinto de. Ensaios sobre algumas enfermidades d'Angola..., op. cit., p. 79.

${ }^{61}$ Idem, Ibidem, p. 125.
} 
relação ao tétano. Neste caso, as sangrias eram sempre nocivas, embora algumas vezes a constituição do enfermo parecesse indicar a necessidade delas. ${ }^{62}$

Desse modo, o médico não se limitava à aplicação às cegas de determinadas terapias; mesmo procedimento adotado em relação às teorias. Se a utilização das flebotomias decerto continuou a fazer parte do repertório da medicina praticada nos domínios ultramarinos portugueses, vários cirurgiões e médicos procuravam utilizá-la em casos específicos de modo a não extenuar mais o corpo dos enfermos. Opinião similar à de José Pinto de Azeredo era a do cirurgião José Antônio Mendes. No seu Governo dos mineiros (1770), escrito a partir das experiências médicas na Capitania das Minas, condenava os excessos das sangrias, observando que essas deviam ser reguladas "conforme as forças, e a fereza do mal o pedem, e também a idade e temperamento". ${ }^{63}$

Recriminando os remédios caseiros e aconselhando o uso moderado das sangrias, Azeredo lançava mão de vários componentes da farmacopeia portuguesa. É o caso da Água de Inglaterra, que ele utilizava em razão de ser feita com uma quina melhor do que a de Angola. ${ }^{64}$ Com o intuito de evitar falsificações, por decreto real de 1799, o controle sobre a fabricação desse remédio destinado às armadas e domínios ultramarinos passou a ser efetuado pela Junta do Protomedicato, sendo produzido nos dispensários farmacêuticos escolhidos para essa finalidade. ${ }^{65} \mathrm{O}$ preparado feito à base da quina teve amplo emprego no combate às febres, tanto em Portugal quanto em suas colônias. Timothy Walker chama atenção para o fato de que a utilização da quina foi imprescindível à expansão ultramarina portuguesa, combatendo enfermidades e impedindo a morte de militares e funcionários coloniais na África. Da Amazônia, no Brasil, foram transplantadas árvores para São Tomé, onde se produzia toneladas de quina enviadas através dos domínios coloniais. ${ }^{66}$

\footnotetext{
${ }^{62}$ Idem, Ibidem, p. 144.

${ }^{63}$ MENDES, José Antônio. Governo dos mineiros, mui necessários aos que vivem distantes de professores seis, oito, dez e mais léguas, padecendo por esta causa os seus domésticos e escravos queixas, que pela dilaçam dos remédios se fazem incuráveis, e as mais das vezes mortais. Lisboa: Officina de Antônio Rodrigues Galhardo, 1770, p. 65. Sobre a trajetória de José Antônio Mendes consultar: RIBEIRO, Márcia Moisés. Nem nobre, nem mecânico..., op. cit.

${ }^{64}$ AZEREDO, José Pinto de. Ensaios sobre algumas enfermidades d'Angola ..., op. cit.,65.

${ }^{65}$ MARQUES, Vera Regina Beltrão. Natureza em boiões: medicinas e boticários no Brasil Setecentista. Campinas/São Paulo: Editora da Unicamp; Centro de Memória-Unicamp, 1999, p. 238-239.

${ }^{66}$ WALKER, Timothy, op. cit., p. 267. Sobre a ampla utilização da quina na farmácia nos domínios portugueses ver também: PITA, João Rui. Mar, farmácia e medicamentos: algumas notas de interesse histórico farmacêutico. In: IX Curso de Verão do ICEA, 2007, p. 1-8. Disponível em: http://www.icea.pt/Actas/ActasiX/Jo\%C3\%A3o_Rui_Pita.pdf. Acesso em 02/06/2001.
} 
Apesar de reconhecer a eficácia dessa droga medicinal, Azeredo sublinhava que algumas febres intermitentes resistiam a ela. Além disso, as dificuldades em obter a quina levaram o médico a buscar alternativas capazes de substituir a matéria prima do medicamento para combater os sintomas da doença. A partir de suas experiências, encontrou na "noz vômica" uma "virtude igual, ou talvez superior à da quina". A descoberta era motivo de orgulho. Nesse sentido, observava que depois de ter comprovado seus efeitos benéficos no hospital "todos os mais professores começaram a receitá-la por necessidade". ${ }^{67}$

Além da "noz vômica", Azeredo recorria ao arsênico branco, substância que, se aplicada com prudência, se mostrava como uma das mais eficazes. Entretanto, pela resistência que a doença oferecia a esses remédios, ele se viu obrigado a colocar em prática "infinitos remédios", vindo depois de frustradas tentativas a encontrar um com reconhecido efeito, a "casca externa do coco" encontrado em Angola e preparada em cozimento. ${ }^{68}$

Nas outras enfermidades de Angola Azeredo agia de maneira semelhante em relação às febres, alternando a aplicação de remédios tradicionais com os descobertos por ele. No caso das disenterias, ministrava a ipecacuanha ou o ruibarbo misturado à quina, bem como a "tintura das cantáridas", substância responsável por não só remover as dores como diminuir a inflamação do intestino. ${ }^{69}$

Da utilização desse amplo receituário se depreende que o médico não apenas salientava o valor de suas descobertas, como incorporava as formulações comuns na medicina portuguesa, compostas por ervas, raízes e substâncias de origem animal - como é o caso da mencionada "tintura de cantárida", obtida de um besouro e utilizada em regiões como a Capitania das Minas. ${ }^{70} \mathrm{~A}$ atitude de Azeredo o aproxima de outros cirurgiões e físicos que se viam obrigados a recorrerem à "botica da natureza" para suprir a ausência de medicamentos disponíveis nas regiões distantes de Portugal e se adequarem às necessidades das doenças endêmicas. ${ }^{71}$

Ao longo do século XVIII se intensificou a utilização de drogas e medicamentos de várias regiões do Império Português. Esse processo de trocas comerciais e incorporação das drogas, obtidas do mundo natural, no receituário lusitano não

\footnotetext{
${ }^{67}$ AZEREDO, José Pinto de. Ensaios sobre algumas enfermidades d'Angola..., op. cit., p. 90.

${ }^{68}$ Idem, Ibidem, p. 92.

${ }^{69}$ Idem, Ibidem, p. 121.

${ }^{70}$ Sobre a utilização dos remédios obtidos da fauna em Minas Gerais ver: SOUZA, Rafael de Freitas e. Medicina e fauna silvestre em Minas Gerais no século XVIII. Varia História, v. 24, n. 39, 2008, p. 273-291.

${ }^{71}$ HOLANDA, Sérgio Buarque de. Caminhos e fronteiras. São Paulo: Companhia das Letras, $3^{\text {a }}$ ed., 1994. Tais questões são abordadas no capítulo "Botica da natureza", p. 74-89.
} 
Jean Luiz Neves ABREU. José Pinto de Azeredo e as Enfermidades de Angola.

estava dissociado do culto racionalizado da exploração da natureza, possibilitado pelos avanços científicos na metrópole portuguesa. ${ }^{72}$

A leitura do Ensaios sobre algumas enfermidades d'Angola permite abordar algumas características do saber médico em fins do século XVIII, fruto tanto do contato com a ciência das Luzes quanto das experiências em regiões do império Português. Com base nesse tratado e outras fontes foi possível identificar algumas das concepções teóricas que exerceram influência na obra de José Pinto de Azeredo e como ele as articulava às suas observações tecidas a partir de sua estadia na América Portuguesa e em Angola. Além disso, cabe perceber como algumas dessas concepções encontravam respaldo na medicina luso-brasileira da época. Não deixa de ser significativo observar também a forma como o médico lida com o conhecimento à sua disposição, ao indicar como esse em muitas ocasiões se mostrou limitado para os casos com os quais se deparou. A despeito do recurso às teorias existentes na medicina, essa atitude é um traço revelador da originalidade de sua obra, levando mais uma vez a rever a ideia da constituição do saber científico luso-brasileiro como mera repetição do praticado nos centros considerados mais avançados da Europa.

Embora pelas fontes consultadas não seja possível saber o impacto da obra de José Pinto de Azeredo na medicina portuguesa, ela permite identificar certos elementos do saber médico praticado no Império Português, produto não só dos contatos com a medicina europeia, mas também de um saber moldado pelas experiências coloniais. $\mathrm{O}$ exame das trajetórias individuais, como a que se pretendeu realizar no âmbito desse artigo, pode fornecer subsídios para a compreensão de como os letrados se apropriavam do conhecimento das Luzes e, ao mesmo tempo, procuravam produzir um saber que fosse capaz de lidar com a realidade colonial. As obras de José Pinto de Azeredo ainda estão por merecer outros estudos e podem desvelar diversas questões que não foram analisadas neste artigo.

Recebido: 08/07/2011 - Aprovado: 02/12/2011

$\overline{72}$ Ver a respeito o estudo de MARQUES, Vera Regina Beltrão, op. cit.; principalmente o capítulo "A natureza decifrada", p. 97-154. 